\title{
INTEGRATION OF OCEAN OBSERVATIONS INTO AN ECOSYSTEM APPROACH TO RESOURCE MANAGEMENT
}

\author{
J. Anthony Koslow ${ }^{(1)}$, Keith Brander ${ }^{(2)}$, Michael Fogarty ${ }^{(3)}$, Frank Schwing ${ }^{(4)}$ \\ ${ }^{(1)}$ Scripps Institution of Oceanography, University of California, S.D., La Jolla, CA 92093-0218, \\ Email: tkoslow@ucsd.edu \\ ${ }^{(2)}$ International Council for the Exploration of the Sea, Copenhagen, Denmark, Email: kbr@aqua.dtu.dk \\ ${ }^{(3)}$ Northeast Fisheries Science Center, NMFS/NOAA, Woods Hole, MA 02543 USA, \\ Email: mfogarty@mercury.wh.whoi.edu \\ ${ }^{(4)}$ Southwest Fisheries Science Center, NMFS/NOAA, Pacific Grove, CA 93950 USA, \\ Email: franklin.schwing@noaa.go
}

\begin{abstract}
Ocean observation programs are integral to the development of integrated ecosystem assessments (IEAs), which provide the scientific basis for ecosystembased management (EBM). Ocean observation programs provide the basis for assessing the state of marine ecosystems and understanding the impacts of natural and anthropogenic forcing. They also underlie the development and testing of ocean models, which provide understanding of marine ecosystem processes and enable prediction of future ecosystem states. Observation programs also serve to monitor the impacts of marine management strategies. We discuss the development of EBM in the USA and Europe and examine the role of ocean observation programs. In particular, we note the need for integrated ocean observation programs that monitor the physical, chemical, and biological state of the oceans, including the zooplankton and mid- to higher trophic levels of large marine ecosystems. The further development of such integrated programs will require cooperation across government, academic and other institutions.
\end{abstract}

\section{INTRODUCTION}

Ocean observation programs serve many societal needs, such as assessing water quality, the state of living marine resources, the influence of climate variability and climate change, and the impacts of various human activities that impinge on the coastal zone and oceans. A further, increasingly important use of ocean observation programs is as the basis for ecosystem-based management $(\mathrm{EBM})$ of fisheries and of marine systems generally.

Conventional fishery management has been based almost entirely on single-species stock assessment, which seeks to maximize long-term yield from a particular fishery in terms of biomass or economic return, treating the population in isolation from its physical and biological environment. This approach has been increasingly criticized, due to its widely perceived failure to sustainably manage global fisheries and the ecosystems they are imbedded within. As a result, there is growing interest in EBM methods [1-6].

Within an EBM framework, the key threats from fisheries include their impacts not only on target species, but on their predators and competitors, on bycatch species and benthic habitats. An EBM-based approach to management further implies that natural drivers of fish populations and ecosystem variability must be distinguished from anthropogenic impacts. The productivity of marine ecosystems and their fisheries vary on interannual (e.g. ENSO (El Niño/Southern Oscillation)), decadal (e.g. the Pacific Decadal, North Pacific Gyre, and North Atlantic Oscillations) and other time scales [7-11]. However, there has been limited success to date incorporating climate variability into fishery management models [12]. Although EBM is often developed within a fisheries context, it should also include the impacts of other marine sector activities: pollution, coastal development, nutrient inputs potentially leading to coastal eutrophication, and introduced species. I

EBM approaches to marine management are now widely mandated, and interest in the subject has grown dramatically, with the number of papers published on the topic doubling approximately every five years since the 1970s (Fig. 1). However, there has been concern that the goals of EBM are vague and difficult to achieve. As a result, there has been considerable effort to operationalize EBM.

It is our purpose in this paper to describe what is meant today by EBM, setting out its conceptual framework, and showing how it is developing into practice. In particular, we will examine the kinds of ocean observations necessary or useful in developing EBM and the role they play within the EBM conceptual framework. 


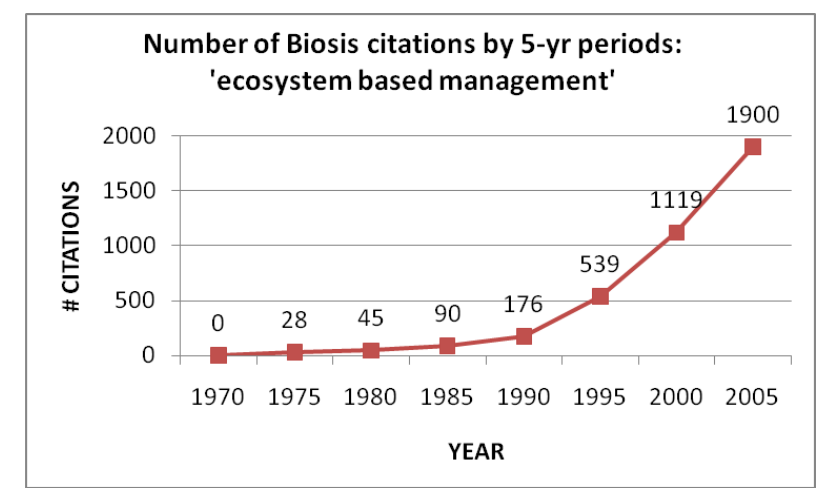

Figure 1. The number of citations in Biosis to 'ecosystem-based management by five-year periods, $1970-2009$.

\section{THE EBM FRAMEWORK AND ITS SCIENTIFIC SUPPORT}

Pikitch et al [3] considered the overall objective of EBM (ecosystem-based management) to "sustain healthy marine ecosystems and the fisheries they support." They broke this down into the following specific issues:

- Avoid degradation of ecosystems as measured by indicators of environmental quality and system status;

- Minimize risk of irreversible change to communities and ecosystem processes;

- Maintain long-term socioeconomic benefits without compromising the ecosystem;

- Generate knowledge of ecosystem processes sufficient to understand the likely consequences of human action. (Emphases added to denote areas requiring observations.)

Although there is reasonable consensus on the overall objectives of EBM, there is considerable divergence on how EBM is to be put into practice. In part this is due to lack of general agreement on what constitute adequate 'indicators of environmental quality and system status' or knowledge 'sufficient to understand the likely consequences of human action' There is also considerable disparity in the level of ocean observation available for different ocean ecosystems, as well as in the types of models used to assess ecosystem understanding and environmental risk.

It is not possible to review here all approaches to EBM. However, marine scientists are increasingly using a methodological rubric known as Integrated Ecosystem Assessments (IEAs) as the scientific underpinning to EBM. References [6 and 13] define an IEA as "a formal synthesis and quantitative analysis of information on relevant natural and socioeconomic factors relative to specified ecosystem management goals." IEAs provide the basis for organizing scientific information and objectively evaluating the benefits and risks of human activity and proposed management options to various ecosystem services and management goals [14].

IEAs explicitly consider all ecosystem components, and address broad EBM goals. In contrast to individualspecies assessments or single-issue management, IEAs consider the impacts of a range of ecological, environmental (including climate change), and human factors to guide resource managers pursuing multiple simultaneous ecosystem and societal objectives. IEAs incorporate human systems as an integral part of the ecosystem not only as a driver of ecosystem processes, but as users of its goods and services. As such, socioeconomic data and models are essential components. They use a formal decision analysis approach that has been proposed as an operational process for marine fisheries management [5, 15 and 16]. However, IEAs evaluate the cumulative effects of multiple, diverse human activities (e.g., fisheries, energy, shipping, coastal development, forestry). The IEA concept is being promoted and applied internationally [17-22]. In this paper, we examine how the IEA concept is being developed in the USA and Europe, but variations on this theme are being developed in Canada, Australia, and other regions where there are 'data-rich' fisheries and marine ecosystems.

\section{DEVELOPMENT OF THE IEA PROCESS IN THE USA}

In the US, the National Oceanic and Atmospheric Administration (NOAA) is implementing IEAs as a critical science-support tool for an Ecosystem Approach to Management (EAM) [13]. Based on a number of national reviews [23-26], NOAA will use an EAM strategy, incorporating ecosystem principles to protect, restore, and manage ocean, coastal and Great Lakes resources [27]. IEAs will be the primary analytical tools to address multi-sector issues in US marine ecosystems, as required by marine spatial planning [28].

The IEA process applied by NOAA will cover five steps (Fig. 2).

1) An initial scoping will identify management objectives, ecosystem attributes of concern, and relevant 
ecosystem stressors.

2) Researchers will develop and test indicators that reflect ecosystem attributes and stressors specified in the scoping process. These must be linked objectively to decision criteria.

3) A hierarchical risk analysis will fully explore the susceptibility of an indicator to natural or human threats, as well as its resilience, the ability of the indicator to return to its previous state after being perturbed. This analysis evolves from a comprehensive but initially qualitative analysis to a highly focused and fully quantitative approach.

4) Results from the risk analysis for each ecosystem indicator are integrated in an ecosystem assessment, which quantifies the overall status of the ecosystem relative to historical status and prescribed targets.

5) The final phase of the IEA is an evaluation of the potential of different management options to influence ecosystem status, using ecosystem models and a formal Management Strategy Evaluation (MSE) [16].

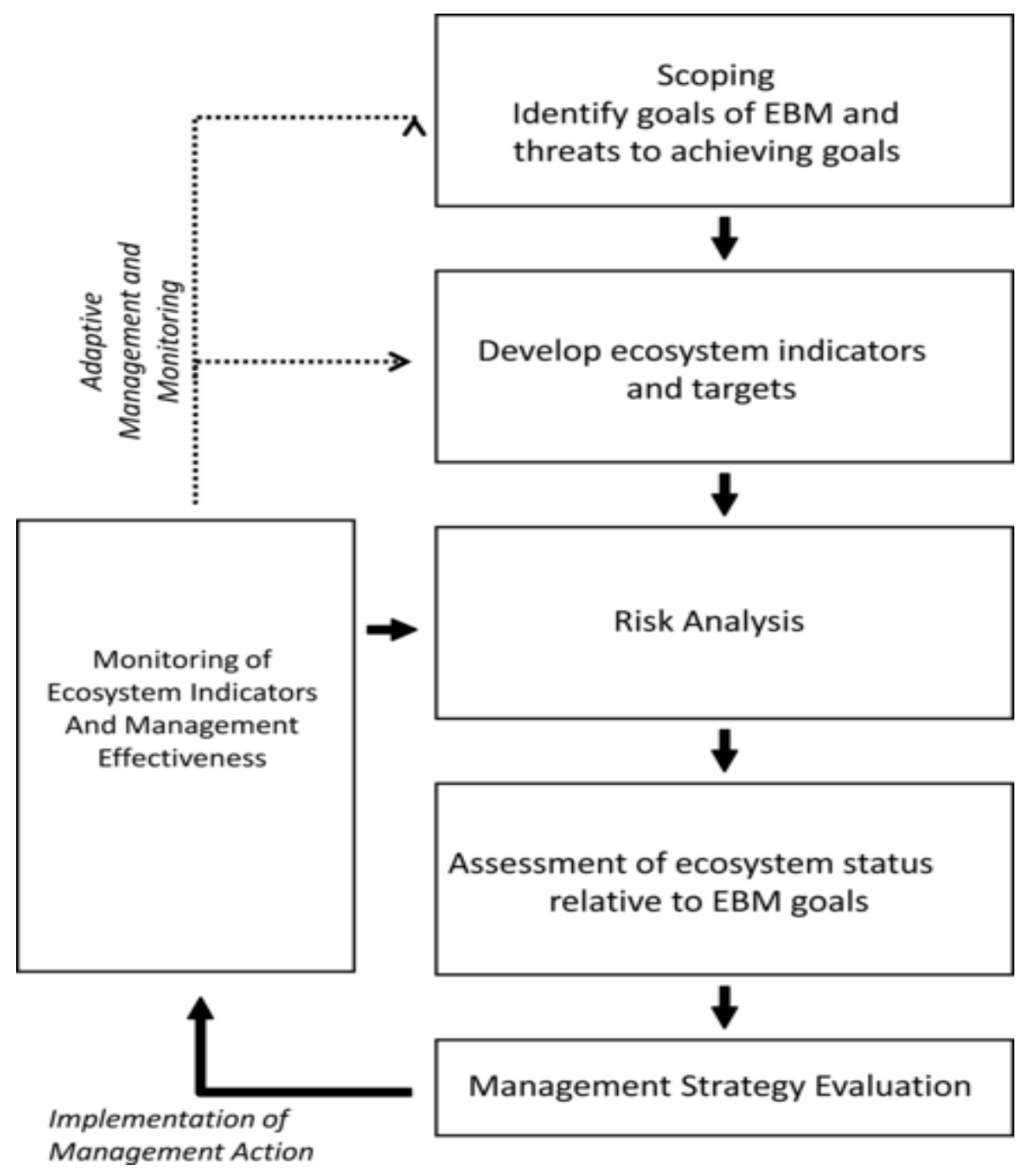

Figure 2. Iterative process of ecosystem-based management. From [6]. 
Achieving the transition to EBM is complicated by the large size of many US marine ecosystems and the geographic scope mandated for their management, and by the global scale of atmospheric and oceanic forcing. It must consider the current single-issue (and scale) management approach, state and federal budget limits, gaps in data, knowledge and information, and a lack of research-management links. While an IEA may focus on a single location, it will consider large-scale issues such as climate change and connectivity between adjacent ecosystems and key management areas within an ecosystem. Therefore, a functional IEA for a particular marine ecosystem can be scaled down to smaller regions to address a different scope of management questions and challenges from the entire ecosystem down to individual reserves. As an integral part of IEAs, observing systems must be able to capture all of these relevant scales.

The IEA process is being pursued in a number of US marine ecosystems. Elements of the IEA framework have been used in the Bering Sea/Gulf of Alaska, Gulf of Mexico, Northeast US, Chesapeake Bay, and California Current ecosystems. Data management frameworks, models, indicators, and condition reports have been developed for various ecosystems.

As one of the first US efforts to employ the full IEA process, the Puget Sound Partnership is a Washingtonbased public-private entity that is working to restore and protect the natural and economic health of the Sound. To date, the process has identified ecosystem indicators and conducted risk assessments and MSEs. There are also a number of ongoing governmental and nongovernmental monitoring efforts in the Puget Sound region. Based on results from the IEA steps, these monitoring efforts may need to be altered or expanded to provide information on key indicators and management effectiveness.

The IEA process will next direct selected management decisions in the California Current. This ecosystem has a long and rich tradition of oceanographic and climate observations (e.g., CalCOFI (California Cooperative Oceanic Fisheries Investigations), US GLOBEC (United States Global Ocean Ecosystems Dynamics)) and ecosystem modeling. The ultimate goal is to implement a dynamic, web-based IEA that will provide a common basis of data, products, and tools to address a variety of management questions at the appropriate scales using the necessary indicators and attributes.

NOAA (National Oceanic and Atmospheric Administration) and its partners will continue to develop and implement an integrated infrastructure for producing IEAs, including computer models that replicate elements and processes of ecosystems to evaluate management options, and web-based data management and integration services that provide data and information to scientists and decision-makers. Ecological observations at several trophic levels must be maintained and enhanced, with a priority on the variables that are demonstrated drivers of ecosystem change. These are crucial to model initialization, validation and assimilation, and to create and produce operational ecological indicators that document ecosystem change and its impacts, essential elements of the US effort to generate and apply regional IEAs.

\section{DEVELOPMENT OF EBM OFF THE NE USA}

To date, development of EBM for the Northeast U.S. Continental Shelf Large Marine Ecosystem (LME) has been largely based on analysis of long-term data sets for the region. Data sets include data from satellites, moorings, continuous plankton recorder surveys, and ship-based ecosystem and fishery surveys that have targeted groundfish, plankton, shellfish, protected species and pelagic species. This LME has undergone large-scale changes due to heavy exploitation by distant- water and domestic fishing fleets over the last five decades. The region has further experienced changes in climate and physical forcing that have contributed to large-scale alteration in ecosystem structure and function. To address the cumulative consequences of these issues and to assess the status of this system, the Northeast Fisheries Science Center has initiated the development of an IEA for this region. The initial phase of this effort has involved the identification of a suite of indicators classified into natural and anthropogenic drivers, resulting pressures, and ecosystem states [29]. Here, drivers are identified as forcing factors such as climate and human population size underlying a constellation of pressures exerted on the system. These pressures include human-related impacts such as removal or degradation of living marine resources through harvesting, shipping, pollution, and impacts on the coastal zone such as habitat loss. Climate-related pressures include changes in atmospheric and oceanographic processes directly or indirectly affecting marine life. Indicators of ecosystem state were then identified that were potentially affected by these drivers and associated pressures with a focus on holistic or integrative metrics of ecosystem condition. Eighteen anthropogenic drivers and pressures were examined, 25 metrics of climate and physical change and 26 indicators of biotic state to characterize change in ecological state on the northeast shelf for the period 1977-2008. To reduce the dimensionality of the problem, integrated measures of each of these three 
classes were constructed using principal components analysis (PCA).

The human component has been a critically important agent of change in this large marine ecosystem. Economic indicators for the groundfish fishery suggest that this resource has been in a long-term state of decline. Trends in human population and disposable income in the region suggest that human induced pressures on marine resources will remain high. (Fig. 3, upper panel).

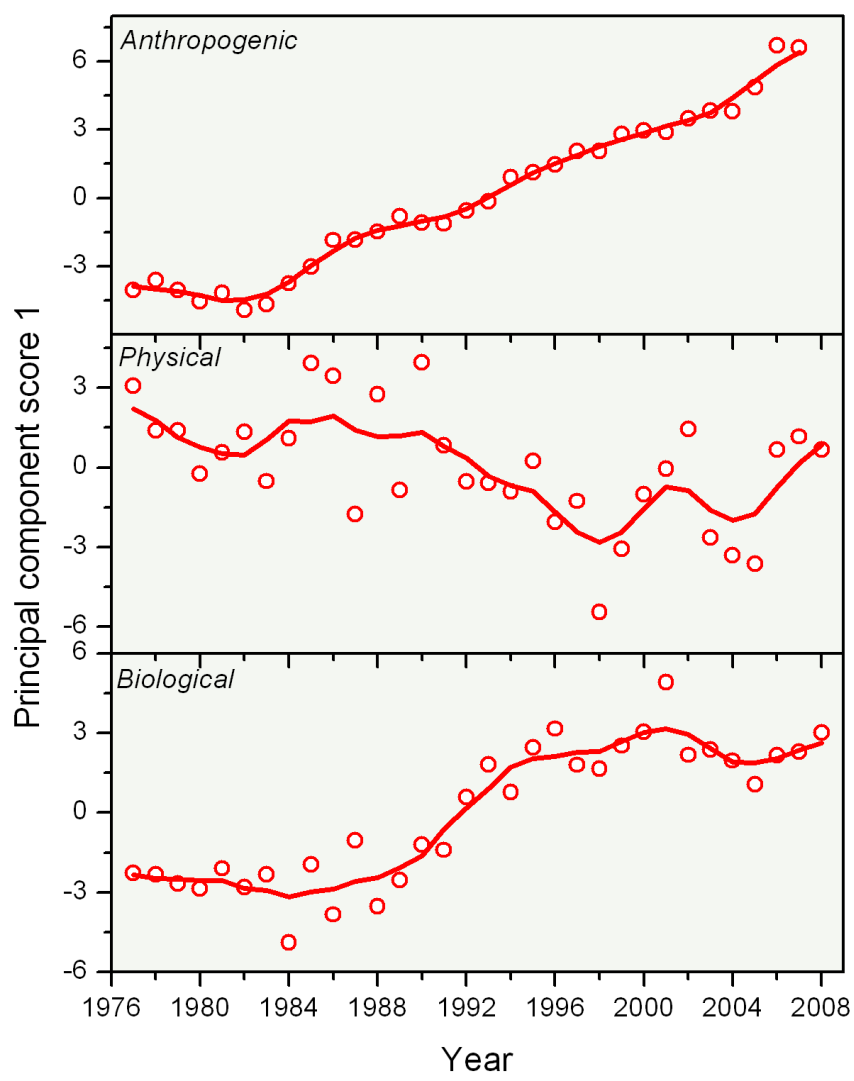

Figure 3. Time trends of the first principal components of anthropogenic, physical, and biotic variables for the Northeast U.S. continental shelf LME.

Decadal and multi-decadal-scale changes in climate and physical forcing factors affecting the ecosystem are evident at a number of levels. Water temperatures have increased in coastal locations and on the continental shelf from a low in the late 1960's to the present. There has been a corresponding increase in high temperature $\left(>16^{\circ} \mathrm{C}\right)$ and a relative decline in intermediate $\left(5-15^{\circ} \mathrm{C}\right)$ thermal habitat available for marine organisms. Increases in temperature and decreases in salinity have led to increases in water column stratification from a low in 1984 to the present that has had a profound effect on primary and secondary productivity. The index of change in climate-related and physical variables based on the first principal component is shown in Fig. 3 (middle panel).

The changes observed in some of the physical variables have been accompanied by clear changes in some of the biotic variables. The decreases in salinity have been accompanied by concomitant changes in an index of larger-bodied phytoplankton species (principally diatoms) in the ecosystem. A related index of water column stratification is closely related to the time series change in the total biomass of zooplankton and changes in the species composition of copepod communities. There has been a pronounced shift from a demersal fishdominated community to one dominated by elasmobranchs and pelagic fish. The fish community has also been affected by a persistent change in conditions that favor temperate-cold water fish to one favoring warmer water species.

The overall biomass of the entire fish community as indexed by trawl surveys has increased over the last four decades as elasmobranchs and small pelagic fishes have increased in abundance even as other groups, such as groundfish, have decreased. Some of these changes reflect apparent species replacements as heavily exploited species declined. The mean trophic level of fish in trawl surveys has fluctuated without trend. In contrast, the mean trophic level of the catch (invertebrates and vertebrates) has declined steadily since 1960, reflecting changes in the abundance of economically important species. The trajectory of overall change in the biotic state variables is shown in Fig. 3 (bottom panel).

Collectively, these results point to dramatic changes in aspects of the structure and function of the Northeast U..S. Continental Shelf. The availability of long-term observing programs for climatic, oceanographic and biotic variables has been a critical advantage in documenting change in the system and in assessing current conditions relative to benchmark levels from earlier periods.

\section{DEVELOPMENT OF THE ECOSYSTEM APPROACH IN EUROPE}

In 2002 the Governments of Norway, Sweden, Denmark, Germany, the Netherlands, Belgium, France, Switzerland, the United Kingdom plus the European Commission signed a declaration (the Bergen Declaration) to establish an ecosystem approach to 
managing the North Sea. The declaration dealt with all uses of and impacts on the marine environment, recognizing that marine ecosystems provide a variety of goods and services, including fisheries. The ecosystem approach acknowledges that different objectives in relation to these goods and services (fisheries, recreation, shipping, pollution, waste, biodiversity, habitat protection) need to be harmonized in terms of policy, governance, science and control. Ministers agreed that fisheries policies and management should move towards the incorporation of ecosystem considerations in a holistic, multiannual and strategic context. The transition towards a full ecosystem approach to fisheries management should be progressive and concomitant with the enhancement of scientific knowledge. The regulations and processes needed to move towards an ecosystem approach were agreed and the adaptive framework, which includes both scientific and policy development, is shown in Fig. 4.

The European Marine Strategy Framework Directive agreed in June 2008 establishes measures to achieve or maintain good environmental status in the marine

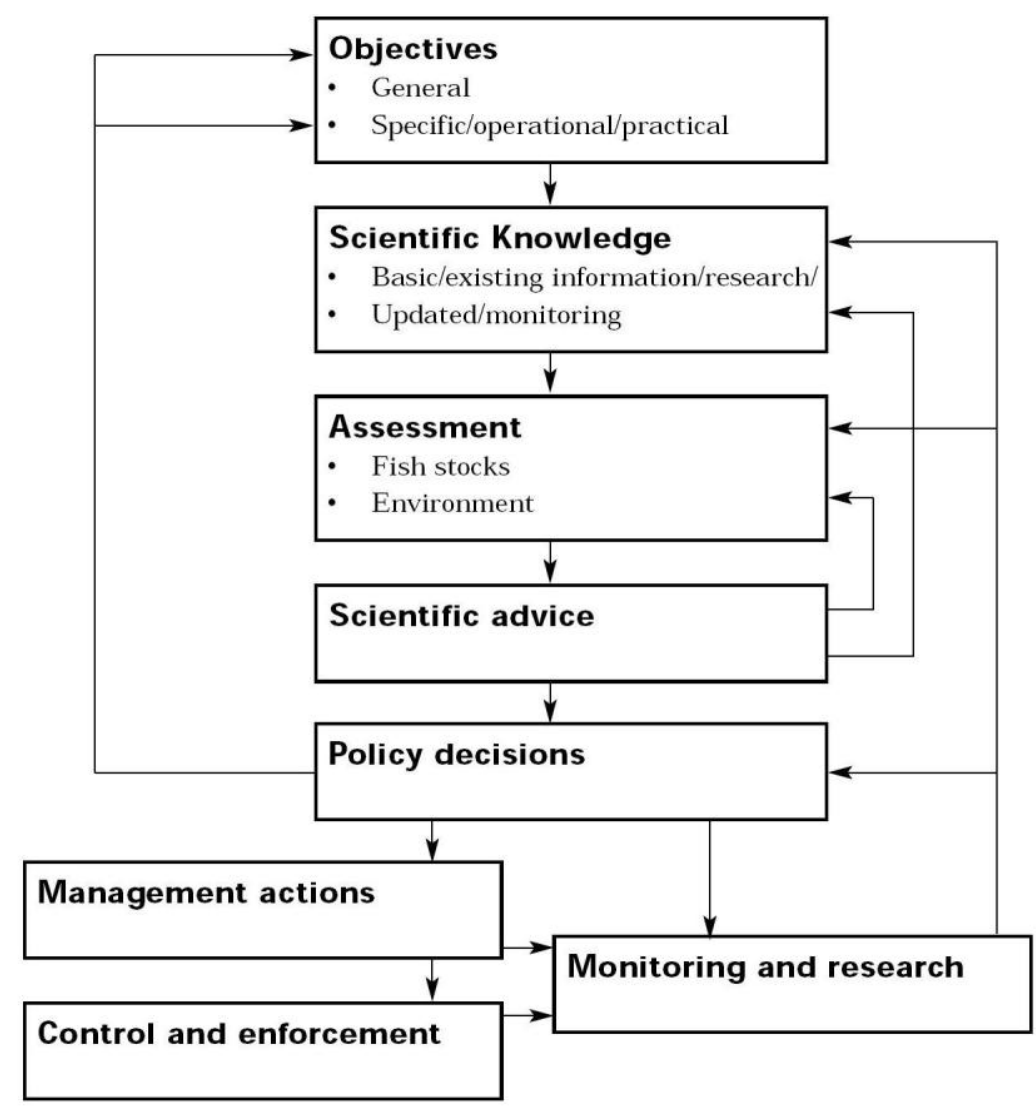

Figure 4. A conceptual framework for an ecosystem approach to the management, protection and restoration of the North Sea. Stakeholders, along with scientists, managers and politicians should be involved at different stages of the decision process to promote openness, transparency and responsibility.

environment by the year 2020 at the latest. This includes the application of an ecosystem-based approach to the management of human activities while enabling a sustainable use of marine goods and services. The Directive focuses on defining the desirable state of marine ecosystems rather than prescribing what regulations and controls are required to achieve this state. It creates a framework that is responsive and adaptive in terms of monitoring, scientific assessment and governance. The Directive sets out eleven descriptors of good environmental status. These address issues and pressures including biodiversity, introduced species, 
eutrophication, seafloor integrity, contaminants, marine litter and underwater noise. For fisheries and marine ecosystems the descriptors state that:

- Populations of all commercially exploited fish and shellfish are within safe biological limits, exhibiting a population age and size distribution that is indicative of a healthy stock.

- All elements of the marine food webs, to the extent that they are known, occur at normal abundance and diversity and levels capable of ensuring the long-term abundance of the species and the retention of their full reproductive capacity.

The eleven qualitative descriptors of good environmental status are being expanded into operational goals and targets to be measured and monitored. They will generate a substantial requirement for routine observations of ocean state.

Three issues arise in relation to fisheries and their interactions within marine ecosystems:

- How do we reconcile harvesting of fish species with impacts that such harvesting may have on marine ecosystems and on other goods and services (e.g. amenity, biodiversity and carbon sequestration)?

- How do we reconcile biological and commercial trade-offs that may arise due to interactions between fish species and their supporting ecosystems (e.g. harvesting one species may adversely affect another species)?

- How do we set management objectives that take account of the changes in marine ecosystems, in particular those due to climate variability and climate change?

A variety of models are being developed to address these questions by including climate and other drivers and by representing marine ecosystems to varying degrees of complexity. While it is possible to include many processes and interactions in such models, most of the functional forms and parameters are poorly known and the resultant complexity can be difficult to understand. An alternative is to construct simpler models that represent interactions implicitly and estimate their values empirically.

The Baltic Sea, a large brackish sea with relatively low species diversity and only three major commercial fish species (cod, sprat and herring) provides an example of such an approach (Fig 5). A simple stochastic food web model was created by fitting a multivariate autoregressive state-space model to a time series of population biomasses, fishing mortalities (F), and a number of abiotic and biotic variables, selected based on prior knowledge of their effects on fish stocks [30]. The sign and strength of the interactions that remain after selection of a parsimonious model are shown in Fig. 5. The model can be used to explore how fishing mortality, environmental factors (particularly salinity change) and biological interactions between fish species and zooplankton species affect the biomass and yields of each species. A further paper (in review) applies projections of future climate to the model in order to assess the probability of extinction of cod under combinations of fishing mortality and salinity change.

These models show how the target and limit reference points for fisheries management must be adjusted to take account of biological interactions and changes in the environment, such as the changes in salinity that may result from global climate change. Ocean observations and operational oceanographic products will help in making such management adjustments particularly since our understanding of the dynamics of salinity and oxygen changes in the Baltic is still far from sufficient to produce credible regional forecasts.

\section{THE OCEAN OBSERVATION MODELING FRAMEWORK FOR EBM}

EBM is still under development in Europe and North America, and its implementation will evolve over the next 5-10 years. In the near-term, the tools need to be developed and tested that link observation systems to IEAs and management. We recommend, following [12], initial regional demonstration projects that are carried out where climate signals and fishery impacts are clearest and where observation systems are already welldeveloped. Ecosystem models must be developed to test climate and management scenarios and to evaluate the adequacy of the observational framework. Ecological indicators of ecosystem status and human impacts need to be developed and tested. Web-based IEAs linked to the regional observation network should be developed.

It is clear that understanding and predicting the impacts of natural variability and human activity on marine ecosystems will potentially require the development of a wide range of models: physical climate models linked to biophysical ecosystem models that incorporate the full ecosystem and its food web dynamics, including the midand higher trophic levels; fishery stock assessment models that enable management strategy evaluation by reflecting the ecosystem impact of fishery management decisions; and socio-economic models that allow the 


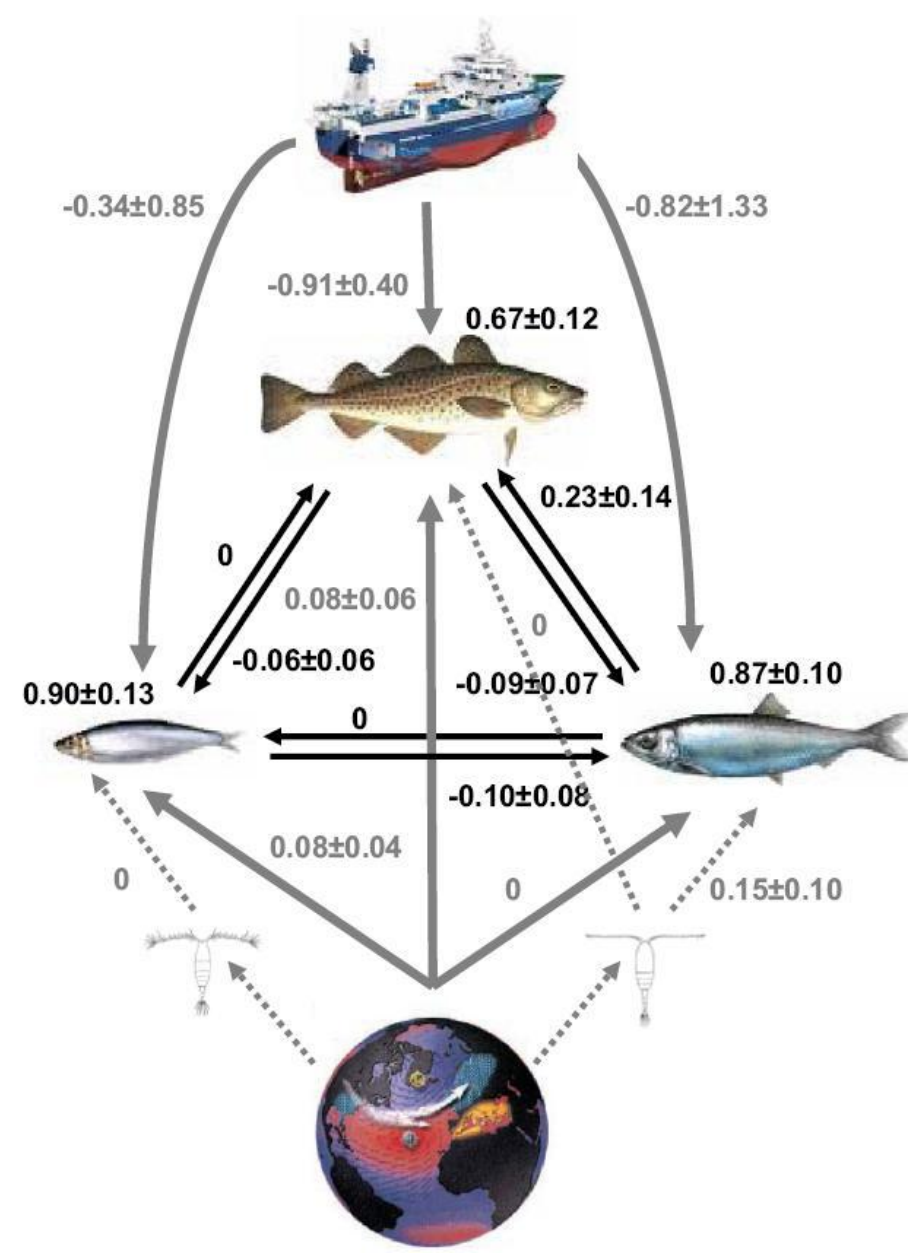

Figure 5. A schematic view of the Baltic Sea upper-trophic food web. Black arrows and parameters represent species interactions between cod (top), sprat (left) and herring (right). Gray arrows and parameters demonstrate the effects of fishing, climate, and zooplankton on the three species. Interactions with the key zooplankton species Acartia spp. (left) and Pseudocalanus acuspes (right) are illustrated by dotted arrows. Negative parameter values indicate negative effects on the biomass of the species. Intraspecific parameters $<1$ indicate an increasing degree of density dependence in the population. Zero parameter values indicate interactions excluded during model selection. The fishery effects on sprat and herring are statistically uncertain but they are heavily exploited and the effects were included. Climate image is from http://www.ldeo.columbia.edu/res/pi/NAO/. 


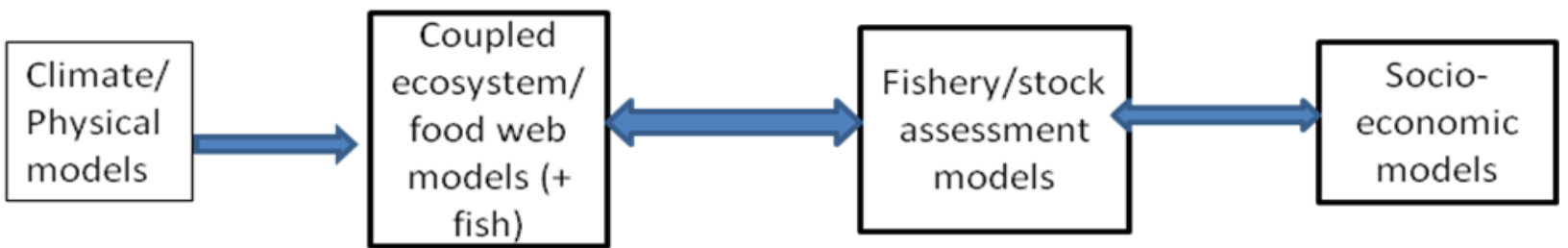

Figure 6. The modeling framework underlying integrated ecosystem assessment, integrating climate/physical model coupled to ecosystem/food web models that must include mid-and higher trophic levels; fishery/stock assessment models; and socioeconomic models that reflect the impact of management decisions. Adapted from [12].

influence of socio-economic decisions to be assessed (Fig. 6). An integrated ocean observation framework must underlie the development and assessment of these models, and the development and monitoring of the IEA and EBM processes generally.

The EBM system is embedded within the global and regional climate and oceanographic assessment observational framework. This includes observations of ocean temperature, sea surface height, and phytoplankton (or its proxies, chlorophyll or ocean color) from a variety of platforms (satellites, moorings, Argo (Array for Realtime Geostrophic Oceanography) floats and gliders, ships) from which ocean circulation, productivity and other properties can be estimated.

However, obtaining the data to parameterize, assimilate into and assess regional ecosystem models above the level of the phytoplankton is more challenging. Some of the longest zooplankton time series are based on Continuous Plankton Recorder (CPR) surveys, and there is a rich scientific literature based on the CPR time series that examines the influence of climate variability on zooplankton community dynamics and relationships between the zooplankton and higher trophic levels [3132]. There is considerable evidence that zooplankton are highly sensitive as sentinel species of climate variability and climate change, due to their relatively short life spans and close links of their life histories to water mass movements [33-34]. However, the CPR data are collected from a single depth and provide a relative index of change in particular taxa, rather than biomass values that can be modeled in relation to phytoplankton dynamics. There are several further zooplankton time series, such as CalCOFI, Line P, and the Newport line off the west coast of North America and others off Japan and the Northeast US, but these are relatively few and differences in sampling complicate synthesis and model development.

Monitoring of fish populations has generally been carried out by fishery agencies. These have often focused on particular species and not been well integrated with oceanographic observations. Mid-trophic levels and noncommercial species have often been neglected, although these are often critical to an ecosystem understanding as key predators, prey and competitors of fishery target species.

There are critical challenges to the future development of EBM in both modeling and observations. The modeling framework for EBM is at the frontier of current marine modeling efforts. High-resolution physical oceanographic models (e.g. based on the Regional Ocean Modeling System or ROMS) have been nested within global climate models. Nutrient-phytoplankton-zooplankton (NPZ) ecosystem models, to which fish have been added, have in turn been nested within such physical models (e.g. ATLANTIS (CSIRO's marine ecosystem model developed by Beth Fulton), NEMURO-FISH (North Pacific Ecosystem Model for Understanding Regional Oceanography-For Including Saury and Herring), and related models [35-36]). However, these models do not yet incorporate the behavior of mid- to higher trophic levels: how, for example, prey fields or mesoscale ocean feature, such as eddies, fronts, and upwelling plumes, influence the distribution of krill, mesopelagic micronekton, pelagic fishes, and other mid- to higher trophic level organisms. Furthermore, these trophodynamic models do not model the recruitment process and thus do not predict the influence of environmental conditions on recruitment to fish populations. Development and testing of such models will require vertically-integrated observation programs, whose observations extend from the physical and chemical ocean environment to its planktonic producers through the mid- and higher trophic levels. The development of such observation systems will require collaboration between modelers and observationalists, as well as between oceanographic and fishery institutions. 


\section{REFERENCES}

1. Link, J. S., et al. 2002. Marine ecosystem assessment in a fisheries management context. Can J Fish Aquat Sci 59: $1429-1440$

2. Browman, H. I., and Stergiou, K. I. 2004. Perspectives on ecosystem-based approaches to the management of marine resources. Marine Ecology Progress Series 274: 269-303.

3. Pikitch, E., et al. 2004. Ecosystem-based fishery management. Science 305: 346-347.

4. Field, J. C., and Francis, R. C. 2006. Considering ecosystem-based fisheries management in the California Current. Marine Policy 30: 552-569.

5. Smith, A. D. M., Fulton, E. A., Hobday, A. J., Smith, D. C., and Shoulder, P. 2007. Scientific tools to support the practical implementation of ecosystem-based fisheries management. ICES Journal of Marine Science 64: 633639.

6. Levin P.S., Fogarty, M.J., Murawski, S.A. and Fluharty D. 2009. Integrated ecosystem assessments: Developing the scientific basis for ecosystem-based management of the ocean. PLoS Biol 7(1): e1000014. doi:10.1371/journal.pbio.1000014

7. Soutar, A., and Isaacs, J. D. 1974. Abundance of pelagic fish during the 19th and 20th centuries as recorded in anaerobic sediment off the California. Fishery Bulletin 72: $257-273$.

8. Lluch-Belda, D., et al. 1989. World wide fluctuations of sardine and anchovy stocks: the regime problem. South African Journal of Marine Science 8: 195-205.

9. Baumgartner, T. R., Soutar, A., and Ferreira-Bartrina, V. 1992. Reconstruction of the history of Pacific sardine and northern anchovy populations over the past two millennia from sediments of the Santa Barbara Basin, California. CALCOFI Reports 33: 24-40.

10. Solow, A. R. 2002. Fisheries recruitment and the North Atlantic Oscillation. Fisheries Research 54: 295-297.

11. Chavez, F. P., Ryan, J., Lluch-Cota, S. E., and Niquen, C. M. 2003. From anchovies to sardines and back: multidecadal change in the Pacific Ocean. Science 299: 217221.

12. Schwing, F. B., Peterson, W. T., Cyr, N., and Osgood, K. E. 2009. Future research requirements for understanding the effects of climate variability on fisheries for their management. In: Beamish, R.J., Rothschild, B.J. (Eds.), The Future of Fisheries Science in North America. Springer Science.

13. Levin, P.S., Fogarty, M.J., Matlock, G.C. and Ernst, M. 2008. Integrated ecosystem assessments. U.S. Dept. Commer., NOAA Tech. Memo. NMFS-NWFSC-92, 20 p.
14. Steffan-Dewenter I, Kessler, M., Barkmann, J., Bos, M.M., Buchori, D. et al. 2007. Tradeoffs between income, biodiversity, and ecosystem functioning during tropical rainforest conversion and agroforestry intensification. Proc. Natl. Acad. Sci. U S A 104: 4973.

15. Caddy, J.F. 1999. Fisheries management in the twenty-first century: Will new paradigms apply? Rev Fish Biol Fish 9: $1-43$.

16. Sainsbury K.J., Punt, A.E. and Smith, A.D.M. 2000. Design of operational management strategies for achieving fishery ecosystem objectives. ICES J Mar Sci 57: 731-741

17. Toth, F. L. 2001. Participatory integrated assessment methods-An assessment of their usefulness to the European Environmental Agency. Tech. Rep. 64, prepared for the European Environment Agency, Copenhagen, Denmark. Online at http://www.eea.europa.eu/publications/Technical report no_64

18. DFO Canada (Dept. Fisheries and Oceans Canada). 2003. State of the eastern Scotian Shelf ecosystem. DFO Canadian Science Advisory Secretariat. Ecosystem Status Rep. 2003/004.

19. DFO Canada (Dept. Fisheries and Oceans Canada). 2005. Guidelines on evaluating ecosystem overview and assessments: Necessary documentation. DFO Canadian Science Advisory Secretariat Rep. 2005/026.

20. Millennium Ecosystem Assessment. 2005. Ecosystems and human well-being: Health synthesis. Available: http://www.who.int/globalchange/ecosystems/ecosystems 05/en/index.html

21. ICES (International Council for the Exploration of the Sea). 2004. Supporting European marine integrated ecosystem assessments: Specific support actions. Copenhagen, Denmark.

22. ICES (International Council for the Exploration of the Sea). 2006. Report of the Regional Ecosystem Study Group of the North Sea (REGNS), 15-19 May 2006. Copenhagen, Denmark. ICES CM 2006/RMC:06.

23. Pew Oceans Commission. 2003. America's Living Oceans: Charting a Course for Sea Change. A Report to the Nation. May 2003. Pew Oceans Commission, Arlington, VA.

24. U.S. Commission on Ocean Policy. 2004. An Ocean Blueprint for the 21 st Century. Final Report. Washington, DC, 2004

25. West Coast Governors' Agreement on Ocean Health. 2006. Final Action Plan for the West Coast Governors' Agreement on Ocean Health. 113 pp.

26. United States Joint Subcommittee on Ocean Science and Technology. 2007. Charting the course for ocean science in the United States for the next decade. Available: http://www.masgc.org/gmrp/plans/JSOST.pdf. 
27. National Oceanic and Atmospheric Administration. 2006.

Evolving an ecosystem approach to science and

management through NOAA and its partners. $85 \mathrm{pp}$.

28. Ehler, C. and Douvere, F. 2009. Marine Spatial Planning: a step-by-step approach toward ecosystem-based management. Intergovernmental Oceanographic Commission and Man and the Biosphere Programme. IOC Manual and Guides No. 53, ICAM Dossier No. 6 Paris: UNESCO.

29. Ecosystem Assessment Program. 2009. Ecosystem Status Report for the Northeast U.S. Continental Shelf Large Marine Ecosystem. Northeast Fisheries Science Center Reference Document 09-11.

30. Lindegren, M., Mollmann, C., Nielsen, A., and Stenseth, N. C. 2009. Preventing the collapse of the Baltic cod stock through an ecosystem-based management approach. Proceedings of the National Academy of Sciences 106: 14722-14727

31. Beaugrand, G., Brander, K. M., Linley, J. A., Souissi, S., and Reid, P. C. 2003. Plankton effect on cod recruitment in the North Sea. Nature 426: 661-664.

32. Richardson, A. J., and Schoeman, D. S. 2004. Climate impact on plankton ecosystems in the northeast Atlantic. Science 305: 1609-1612.

33. Planque, B., and Taylor, A. H. 1998. Long-term changes in zooplankton and the climate of the North Atlantic. ICES Journal of Marine Science 55: 644-654.

34. Brinton, E., and Townsend, A. 2003. Decadal variability in abundances of the dominant euphausiid species in southern sectors of the California Current. Deep-Sea Research II 50: 2449-2472.

35. Fulton, E. A., Parslow, J. S., Smith, A. D. M., and Johnson, C. R. 2004. Biogeochemical marine ecosystem models. 2. The effect of physiological detail on model performance. Ecological Modelling 173: 371-406.

36. Megrey, B. A., et al. 2007. A bioenergetics-based population dynamics model of Pacific herring (Clupea harengus pallasii) coupled to a lower trophic level nutrient-phytoplankton-zooplankton model: Description, calibration and sensitivity analysis. Ecological Modelling 202: $144-164$. 